\title{
Metallographic analysis of the internal microstructure of orthodontic mini-implants
}

Flávio Augusto Cotrim-Ferreira(a) Camila Leite Quaglio(b)

Rubén Patricio Vásquez Peralta ${ }^{(c)}$ Paulo Eduardo Guedes Carvalho(a) Danilo Furquim Siqueira ${ }^{(a)}$

(a) Department of Orthodontics, University of São Paulo City (UNICID), São Paulo, SP, Brazil.

(b) DDS.

(c) Dental School of University of São Paulo City (UNICID), São Paulo, SP, Brazil.

\section{Corresponding author:}

Camila Leite Quaglio

Universidade Cidade de São Paulo

Rua Cesário Galeno, 448/475,

Tatuapé

São Paulo - SP - Brazil

CEP: 03071-000

E-mail:cquaglio@yahoo.com.br

Received for publication on Mar 09, 2010

Accepted for publication on Jul 06, 2010

\begin{abstract}
Effective orthodontic anchorage may be obtained by miniimplants inserted into the maxillary bones. However, the risk of miniimplant failure is one of the most important issues, especially the rupture of its structure referred to as fracture, mainly due to metal deficiencies. This study analyzed the internal microstructure of orthodontic mini-implants, ascertaining the composition of the metal to detect possible discontinuities from the surface to the core of the screws. Eighteen samples of mini-implants, of 3 different brands, were obtained. The samples were cold-embedded in methyl methacrylate polymer, and were sectioned both longitudinally (3 samples of each brand) and transversely (the other 3 screws of each brand). After preparation, the samples were observed using a light microscope at up to 2,000 x magnification. The results showed that the mini-implants thus analyzed were composed of an Alpha-Beta globular phase of titanium alloy, patterns A1 and A9 (in accordance with the "Technical Committee of European Titanium Producers"). The miniimplants did not present any defects such as bubbles, imperfections or fissures, in either longitudinal or transverse sections, in their internal microstructure. All samples met the requirements of international norms. Orthodontists must be aware of the metal composition and internal microstructure of mini-implants, to decrease the risk of fractures.
\end{abstract}

Descriptors: Orthodontics; Dental Implantation; Orthodontic Anchorage Procedures.

\section{Introduction}

Anchorage is a fundamental part of orthodontic treatment. Orthodontic anchorage is commonly provided by other teeth, or by extraoral and intraoral devices. These orthodontic anchorage systems are limited by several factors, including complicated biomechanics and degree of patient compliance. ${ }^{1-3}$ When maximum anchorage is necessary, the miniimplants appear to be a new alternative in orthodontic treatment, since these devices are inserted in the bone providing effective anchorage (skeletal anchorage). ${ }^{2,4}$

Many studies have evaluated the clinical success of this orthodontic device. The majority of studies address the external structure of the mini-implant as well as its diameter and length; $;^{5,6}$ type; ${ }^{1,6,7}$ and mechanical resistance. ${ }^{8}$ Other studies in the literature commonly discuss the surgical procedure; ${ }^{9-11}$ mini-implant direction of placement; ${ }^{6}$ force applied 
to the mini-implant; ${ }^{6,12}$ osseointegration; ${ }^{13}$ sites of insertion $^{5,9}$ and characteristics of the patient. ${ }^{5,6,14,15}$ However, studies on the internal microstructure of the mini-implant are uncommon in the literature.

Many systematic reviews of mini-implants have been conducted. ${ }^{16-19}$ The more recent systematic reviews have considered mini-implant fractures. ${ }^{19}$ These fractures occur mainly during procedures for placement and removal. ${ }^{19}$ In addition to the torsional strength and size of the mini-implant, ${ }^{19}$ their material and internal microstructure can also contribute to fractures.

The material used for implants must be nontoxic and biocompatible; should have good mechanical properties; and be able to resist stress, strain, and corrosion. ${ }^{16,17}$ Commercially pure titanium (cp Ti) is the answer to all these needs. Nevertheless, miniimplants are very thin structures and must bear high orthodontic loads, thus requiring fracture resistance. In order to overcome these factors, a titanium alloy was made by incorporating aluminum $(\mathrm{Al})$ and vanadium $(\mathrm{V})$ along with the cp Ti (Ti-6Al-4V). This titanium alloy provides greater strength and fatigue resistance than the $\mathrm{cp} \mathrm{Ti},{ }^{20}$ while maintaining the corrosion resistance ${ }^{21}$ and low toxicity. ${ }^{22}$

To minimize the risk of fracture, the internal microstructure of a mini-implant must be homogeneous and free of discontinuities. Because of the importance of this issue, this study evaluated the internal microstructure of mini-implants, ascertaining the composition of the metal structure, thus detecting possible discontinuities from the surface to the core of the screws.

\section{Material and Methods}

The metallographic analysis of the internal microstructure was done using Ti-6Al-4V (Ti grade 5) orthodontic mini-implants from three different dental implant manufacturing companies. The samples comprised eighteen self-drilling mini-implants divided into 3 groups: Group 1 with six samples of OSAS (DEWIMED ${ }^{\circledR}$ - Tuttlingen, Baden-Württemberg, Germany) having 1.6-mm diameter, 9.0$\mathrm{mm}$ length and a transmucosal collar of $2.5 \mathrm{~mm}$; Group 2 with six samples of Wire Dynamic (SIN ${ }^{\circledR}$
- São Paulo, São Paulo, Brazil), having 1.4-mm diameter, 8.0-in length and a transmucosal collar of $1.00 \mathrm{~mm}$; and Group 3 with six samples of Ortoimplante Convencional $\left(\mathrm{CONEX}^{\mathrm{A} O}{ }^{\circledR}\right.$, Arujá, São Paulo, Brazil), having $1.5-\mathrm{mm}$ diameter, $9.0-\mathrm{mm}$ length and a transmucosal collar of $1.0 \mathrm{~mm}$. All samples were supplied from 2 distinct batches by each company.

The methodology applied in this study was based on the "American Society for Testing and Materials" (ASTM International). The standards applied were ASTM E3-01 (Standard Guide for Preparation of Metallographic Specimens), ${ }^{23}$ ASTM E7-03 (Standard Terminology Relating to Metallography), ${ }^{24}$ and ASTM E407-99 (Standard Practice for Microetching Metals and Alloys). ${ }^{25}$ Another standard applied was from "International Organization for Standardization”, ISO 5832-3 (Implants for surgery - Metallic materials Part 3). ${ }^{26}$

The samples were cold-embedded in methyl methacrylate polymer before being longitudinally sectioned (3 samples from each brand) and transversely sectioned (3 samples from each brand) with a circular table saw (Arotec $^{\circledR}$ - São Paulo, São Paulo, Brazil) and a cutting disc (Norton ${ }^{\circledR}$ - Worcester, Massachusetts, USA). Successively, the mini-implants were sanded in a round device with sandpapers of decreasing grains $(150,220,320,400$ and 600 abrasive grains) (Arotec ${ }^{\circledR}$ - São Paulo, São Paulo, Brazil), using water as a lubricant, to obtain a plain and homogeneous surface. The samples were polished in a sander, using a diamond abrasive paste with grains of $6 \mu \mathrm{m}, 3 \mu \mathrm{m}$ and $1 \mu \mathrm{m}$ (Arotec ${ }^{\circledR}$ - São Paulo, São Paulo, Brazil).

After this first stage, a chemical preparation was prepared to show the two distinct phases, Alpha and Beta, of the internal microstructure of the mini-implants. The solution reacted with the samples during contact for twenty seconds. After that, the samples were dried with hot air.

\section{Longitudinally sectioned mini-implants}

The chemical treatment of the longitudinally sectioned mini-implants was done with Kroll's reactive solution, composed of $10 \mathrm{ml} \mathrm{HF}, 5 \mathrm{ml} \mathrm{HNO}_{3}$ and 
$85 \mathrm{ml} \mathrm{H}_{2} \mathrm{O}$. They were analyzed to detect bubbles, imperfections and fissures of the cores and screws of the mini-implants.

The longitudinally sectioned mini-implants were analyzed at $50 \mathrm{x}$ and $400 \mathrm{x}$ magnification.

\section{Transversely sectioned mini-implants}

In order to observe the transversely sectioned mini-implants, the chemical treatment was done with a solution composed of $6 \mathrm{~g}$ of $\mathrm{NaOH}, 60 \mathrm{ml}$ of $\mathrm{H}_{2} \mathrm{O}$ and $10 \mathrm{ml}$ of $\mathrm{H}_{2} \mathrm{O}_{2}$. This process revealed the internal microstructure of the mini-implants, in which an effective contrast of the Alpha and Beta phases was provided. The Alpha-Beta phases analyzed in this way were compared with the European technical norms (ETTC-2) published by the "Technical Committee of European Titanium Producers". This manual presents microphotographs that represent the Ti-6Al-4V bars on transversely sectioned samples, evaluated using a light microscope at 2,000 x magnification. The arrangement of the internal microstructure of Alpha-Beta phase is classified between A1 and A24. The ETTC-2 is considered adequate only to the patterns scored between A1 to A10 for the manufacturing of orthodontic mini-implants. The patterns A1 to A10 show a clear distinction of the Alpha and Beta phases, granules of reduced size and both phases in percentage equilibrium. These factors provide a high quality of the internal microstructure of the titanium alloy.

The internal microstructure of the mini-implants was analyzed at 2,000 x magnification.

\section{Results}

All analyses were performed in a specialized laboratory for characterization and material testing, named TORK (Controle Tecnológico de Materiais Ltda, São Paulo, SP, Brazil).

\section{Longitudinally sectioned mini-implants}

The internal microstructures of the three groups were homogeneous and free of discontinuities. There were no defects in either the cores or the screws of any mini-implants evaluated.

\section{Transversely sectioned mini-implants}

The metallographic analysis of transversely sectioned samples was based on the ISO 5832-3 norm (Implants for surgery - Metallic materials - Part 3).

The three groups presented bimodal microstructure with Alpha-Beta phase ranging between patterns A1 and A9, as described in the ETTC-2. Therefore, the norms of the ETTC-2 manual, established by "Technical Committee of European Titanium Producers", were met.

The DEWIMED ${ }^{\circledR}$ and SIN $^{\circledR}$ mini-implants were classified as A1 pattern. The CONEXÃO ${ }^{\circledR}$ mini-implants were classified as A9 pattern.

\section{Discussion}

Mini-implants are already a proven device to provide the anchorage control in orthodontic treatment. The available studies are focused on minimizing problems and unsuccessful procedures. One of the problems is mini-implant fracture, which is a big concern among orthodontists. The literature showed that fractures may occur because of the torsional strength and small diameter of the mini-implant. ${ }^{4,19}$ The internal microstructure of the mini-implants is also an important aspect to be considered since bubbles, imperfections and fissures could induce fractures, mainly during the placement and removal procedures.

Another factor related to the risk of mini-implant fracture is the titanium alloy composition, manufactured as a fusion of Alpha and Beta phases. The Alpha phase presents mechanical resilience and tenacity, but low ductility. The Beta phase presents good formability and fatigue resistance at high and low temperatures, but it is highly vulnerable to atmospheric contamination. Because of the advantages of these two phases, the titanium alloy for miniimplants is composed of both phases in equilibrium (Ti-6Al-4V). The Alpha phase is represented by $6 \%$ of aluminum and the Beta phase is represented by $4 \%$ of vanadium. The Alpha-Beta phase in the titanium alloy allows a considerable increase of fracture limits.

The literature reviewed did not include studies about the internal microstructure or the titanium al- 
loy (Alpha-Beta phase) of mini-implants. These factors encouraged the pursuit of this study.

The mini-implants selected are the best-selling of the three companies (DEWIMED ${ }^{\circledR}, \mathrm{SIN}^{\circledR}$ and CONEXÃO ${ }^{\circledR}$ ) in Brazil. The diameter and length selected were clinically adequate for orthodontic treatment. ${ }^{4}$

\section{Longitudinally sectioned mini-implants}

The results of longitudinally sectioned mini-implants showed homogeneous microstructures, free of discontinuities. There were no defects in the cores or in the screws of any mini-implants evaluated. This factor probably decreases the risk of mini-implant fracture, due to the homogeneous internal microstructure of the mini-implants.

\section{Transversely sectioned mini-implants}

The metallographic analysis of transversely sectioned mini-implants showed that all samples presented patterns of Alpha-Beta phase, according to the "Technical Committee of European Titanium Producers" described in ETTC-2 (patterns between A1 and A10). The DEWIMED ${ }^{\circledR}$ (group 1) and SIN ${ }^{\circledR}$ (group 2) showed the pattern A1 metallographic arrangement. This pattern has a predominance of the Alpha phase. The CONEXÃO ${ }^{\circledR}$ (group 3) showed the pattern A9, indicating predominance of Beta phase.

The Alpha phase is generally not heat treated and but is weldable. This phase presents higher corrosion resistance and good toughness, bending and flow resistance at high temperatures. The Beta phase has low elastic modulus and superior corrosion resistance. The Alpha-Beta phase does not have good flow resistance at high temperatures, but presents good properties for plastic forming. ${ }^{27,28}$

The results of this study showed that the miniimplants from CONEXÃO ${ }^{\circledast}$ presented different metallographic composition (pattern A9) compared to mini-implants from DEWIMED ${ }^{\circledR}$ and SIN ${ }^{\circledR}$ (pattern A1). This fact probably interferes with toughness of folding, yield strength and elastic modulus, since the quantity of alpha and beta phases are distinct among the groups.

This distinct metallographic composition in groups 1 and 2, as compared to group 3, probably indicates different mechanical properties. However, these results cannot be interpreted to suggest that any brand has a higher risk of fracture than others, since the patterns A1 to A10 are approved by the "Technical Committee of European Titanium Producers".

Metallographic composition is one of many factors that influence the risk of fracture. There are other aspects as well, such as: the transverse dimension of the mini-implant core, the geometry of the active part, and the design and dimension of the screws. Thus, further studies about the physical characteristics of mini-implants are needed in order to better characterize the mechanical properties of these important orthodontic devices.

\section{Clinical implication}

Effective anchorage by mini-implants has achieved widespread acceptance in orthodontic treatment. However, mini-implant failure remains a concern in orthodontics. ${ }^{1,6,14}$ One of the types of failure is the fracture of mini-implants. Orthodontists should not only be aware of the size and torsional strength of mini-implants ${ }^{4,19}$ but should also consider the material and internal microstructure of the mini-implants. Practitioners must know the properties of mini-implants in order to increase the success rates of their procedures.

\section{Conclusion}

Based on the methodology used to evaluate the internal microstructure of the mini-implants from DEWIMED $^{\circledast}, \mathrm{SIN}^{\circledast}$ and CONEXÃO ${ }^{\circledast}$, the following could be concluded:

- All longitudinally sectioned samples had a homogeneous internal microstructure, free of discontinuities. The transversely sectioned mini-implants met the norms established by the "Technical Committee of European Titanium Producers";

- the metal composition and internal microstructure of mini-implants are important factors to be evaluated, in order to improve the mechanical properties and decrease the risk of mini-implant fracture. 


\section{References}

1. Chen YJ, Chang HH, Huang CY, Hung HC, Lai EH, Yao CC. A retrospective analysis of the failure rate of three different orthodontic skeletal anchorage systems. Clin Oral Implants Res. 2007 Dec;18(6):768-75.

2. Yao CC, Lai EH, Chang JZ, Chen I, Chen YJ. Comparison of treatment outcomes between skeletal anchorage and extraoral anchorage in adults with maxillary dentoalveolar protrusion. Am J Orthod Dentofacial Orthop. 2008 Nov;134(5):61524.

3. Wu TY, Kuang SH, Wu CH. Factors associated with the stability of mini-implants for orthodontic anchorage: a study of 414 samples in Taiwan. J Oral Maxillofac Surg. 2009 Aug;67(8):1595-9.

4. Papadopoulos MA, Tarawneh F. The use of miniscrew implants for temporary skeletal anchorage in orthodontics: a comprehensive review. Oral Surg Oral Med Oral Pathol Oral Radiol Endod. 2007 May;103(5):e6-15.

5. Miyawaki S, Koyama I, Inoue M, Mishima K, Sugahara T, Takano-Yamamoto T. Factors associated with the stability of titanium screws placed in the posterior region for orthodontic anchorage. Am J Orthod Dentofacial Orthop. 2003 Oct;124(4):373-8.

6. Park HS, Jeong SH, Kwon OW. Factors affecting the clinical success of screw implants used as orthodontic anchorage. Am J Orthod Dentofacial Orthop. 2006 Jul;130(1):18-25.

7. Chaddad K, Ferreira AF, Geurs N, Reddy MS. Influence of surface characteristics on survival rates of mini-implants. Angle Orthod. 2008 Jan;78(1):107-13.

8. Carano A, Velo S, Incorvati C, Poggio P. Clinical applications of the Mini-Screw-Anchorage-System (M.A.S.) in the maxillary alveolar bone. Prog Orthod. 2004;5(2):212-35.

9. Wilmes B, Su YY, Drescher D. Insertion angle impact on primary stability of orthodontic mini-implants. Angle Orthod. 2008;78(6):1065-70.

10. Estelita S, Janson G, Chiqueto K, Janson M, de Freitas MR. Predictable drill-free screw positioning with a graduated 3-dimensional radiographic-surgical guide: a preliminary report. Am J Orthod Dentofacial Orthop. 2009 Nov;136(5):72235.

11. Noble J, Karaiskos NE, Hassard TH, Hechter FJ, Wiltshire WA. Stress on bone from placement and removal of orthodontic miniscrews at different angulations. J Clin Orthod. 2009 May;43(5):332-4.

12. Carano A, Velo S, Leone P, Siciliani G. Clinical applications of the Miniscrew Anchorage System. J Clin Orthod. 2005 Jan;39(1):9-24; quiz 9-30.

13. Melsen B, Lang NP. Biological reactions of alveolar bone to orthodontic loading of oral implants. Clin Oral Implants Res. $2001 \mathrm{Apr} ; 12(2): 144-52$.

14. Apel S, Apel C, Morea C, Tortamano A, Dominguez GC, Conrads G. Microflora associated with successful and failed orthodontic mini-implants. Clin Oral Implants Res. 2009 Aug 30;20(11):1186-90.

15. Santiago RC, de Paula FO, Fraga MR, Picorelli Assis NM, Vitral RW. Correlation between miniscrew stability and bone mineral density in orthodontic patients. Am J Orthod Dentofacial Orthop. 2009 Aug;136(2):243-50.

16. Favero L, Brollo P, Bressan E. Orthodontic anchorage with specific fixtures: related study analysis. Am J Orthod Dentofacial Orthop. 2002 Jul;122(1):84-94.

17. Huang LH, Shotwell JL, Wang HL. Dental implants for orthodontic anchorage. Am J Orthod Dentofacial Orthop. 2005 Jun;127(6):713-22.

18. Feldmann I, Bondemark L. Orthodontic anchorage: a systematic review. Angle Orthod. 2006 Aug;76(3):493-501.

19. Reynders R, Ronchi L, Bipat S. Mini-implants in orthodontics: a systematic review of the literature. Am J Orthod Dentofacial Orthop. 2009 May;135(5):564 e1-19; discussion 564-5.

20. Morais LS, Serra GG, Muller CA, Andrade LR, Palermo EF, Elias CN et al.. Titanium alloy mini-implants for orthodontic anchorage: immediate loading and metal ion release. Acta Biomater. 2007 May;3(3):331-9.

21. Kuphasuk C, Oshida Y, Andres CJ, Hovijitra ST, Barco MT, Brown DT. Electrochemical corrosion of titanium and titanium-based alloys. J Prosthet Dent. 2001Feb;85(2):195-202.

22. Morais LS, Serra GG, Albuquerque Palermo EF, Andrade LR, Muller CA, Meyers MA, et al. Systemic levels of metallic ions released from orthodontic mini-implants. Am J Orthod Dentofacial Orthop. 2009 Apr;135(4):522-9.

23. American Society for Testing and Materials. ASTM E3 - 01 Standard Guide for Preparation of Metallographic Specimens. West Conshohocken: American Society for Testing and Materials; 2007. 12 p.

24. American Society for Testing and Materials. ASTM E7 - 03 Standard Terminology Relating to Metallography. West Conshohocken: American Society for Testing and Materials; 2009. $30 \mathrm{p}$.

25. American Society for Testing and Materials. ASTM E407-99 Standard Practice for Microetching Metals and Alloys. West Conshohocken: American Society for Testing and Materials; 1999. $21 \mathrm{p}$.

26. International Organization for Standardization. Implants for surgery - Metallic materials Part 3: Wrought titanium 6-aluminium 4-vanadium alloy International Organization for Standardization. Reference number ISO 5832-3. Geneva: ISO; 1996.

27. Bania PJ. Titanium alloys in the 1990's. In: Eylon D, Boyer RR, Koss DA, editors. Warrendale, PA: The Mineral, Metals \& Materials Society; 1993. p. 3-4.

28. Schutz RW. Beta titanium alloys in the 1990's. In: Eylon D, Boyer RR, Koss DA, editors. Warrendale, PA: The Mineral, Metals \& Materials Society; 1993. p. 75-91. 